\title{
SUPERVIVENCIA EN UNA BARRIADA EN LA CIUDAD DE MÉXICO
}

\author{
LARISSA LOMNITZ * \\ Universidad Nacional Autónoma de México
}

ENTRE LOS PREjuICIOS más arraigados en la literatura sociológica acerca del problema de la pobreza, se encuentra aquel que retrata a los pobres como afectos a toda clase de patologías sociales, cuyo cuadro general se resume en una pretendida incapacidad para responder adecuadamente a los estímulos socioeconómicos. Valentine (1968) ha examinado críticamente este punto de vista y señalado los errores conceptuales y metodológicos que contiene. El presente trabajo trata de un sector de la población urbana de México conocido como los "marginados", es decir, los que Quijano (1971) designa bajo la categoría de "población sobrante de las economías capitalistas dependientes". Lewis se ha encargado de pintar con lujo de detalles el modo de vida de ciertos sectores de este grupo social (Lewis, 1959; 1960; 1961; 1964; 1969). Nuestro objetivo, en cambio, consiste en ir más allá de un mero inventario de lacras y carencias, para plantearnos la siguiente pregunta: ¿cuáles son los mecanismos que permiten a millones de latinoamericanos, básicamente huérfanos de toda protección social, subsistir en barriadas a pesar de una notoria falta de ahorros y de aptitudes para ganarse la vida en un medio urbano industrial?

El hecho que un grupo humano tan numeroso logre sobrevivir en las condiciones extremas de la marginalidad latinoamericana tiene implicaciones teóricas importantes. Desde luego, los integrantes de tal grupo no pueden seguirse considerando como "menos aptos", en ningún sentido valedero, La proliferación de las barriadas en América Latina indica, por el contrario, que estas barriadas responden a necesidades sociales objetivas (Mangin, 1967; Mangin y Turner, 1968). Mi trabajo de campo en una barriada de la ciudad de México me ha llevado a concebir estas aglomeraciones humanas, aparentemente caóticas, como campos de gestación de una forma de organización social perfectamente adaptada a las necesidades de superviencia en las condiciones socioeconómicas propias de fla marginalidad. Concretamente, espero demostrar que son las redes de intercambio desarrolladas por los pobladores las que constituyen un mecanismo efectivo para suplir la falta de seguridad económica que prevalece en la barriada. Estas redes representan un esquema de organización social específico de la barriada: aparecen junto con la condición de mar-

* Agradezco al Dr. Joaquín Cravioto y al Dr. Luis Rangel, del Hospital Infantil de México, su apoyo en la etapa inicial del estudio. El Dr. Ángel Palerm, de la Universidad Iberoamericana, patrocinó este trabajo en sus aspectos académicos. La terminación de la investigación no hubiera sido posible sin el apoyo económico de la Fundación Wenner-Gren y del Consejo Nacional de Ciencia y Tecnología. 
ginalidad y desaparecen cuando los marginados logran integrarse al proletariado urbano. En otras palabras, representan una respuesta de tipo evolutivo a las condiciones socioeconómicas de la marginalidad.

Este estudio es el resultado de dos años de trabajo en una barriada. Existen otras descripciones de barriadas en América Latina (Leeds, 1969; Matos Mar, 1968; Nichamin, 1968; Bonilla, 1961; Safa, 1964; Roberts, 1968; Pattie, 1968; Portes, 1972), y espero que el presente trabajo aporte corroboraciones y nuevos puntos de vista al conjunto de documentos sobre marginalidad. Conforme a la tradición antropológica, me he basado principalmente en la observación participante y en entrevistas no estructuradas, para bosquejar en forma global la historia de una barriada, la personalidad de sus pobladores y su organización socioeconómica. Sin embargo, he combinado este enfoque con un amplio trabajo sociológico, consistente en encuestas de todas las unidades domésticas en la barriada. Esta combinacion de metodólogías antropológicas y socioógicas es indispensable en ta ciưăad, donde no es posible suponer el mismo grado de homogeneidad socialy cultural que existe, por ejemplo, en el campo. La observación participante se ha usade para estructurar et modelo mecánico, el que posteriormente ha sido completado y rellenado mediante el modelo estadístico derivado de encuestas sociológicas, siguiendö lăs sugerencias de Levi-Strauss (1967).

\section{Cerrada del Cóndor}

La barriada de Cerrada del Cóndor se extiende en la ladera de una barranca del sur del Distrito Federal, frente a un panteón en la ladera opuesta. La barranca representa el límite natural entre dos colonias de clase media de origen relativamente reciente, ubicadas en los lomajes al sur de la antigua villa de Mixcoac. Antes de 1940 esta zona había sido campestre, y su actividad económica se limitaba a unos viveros y a la explotación de minas de arena en la barranca.

Los primeros pobladores adquirieron, hacia 1930, un terreno seco y estéril que forma la propiedad actual de la barriada. Esta familia se avecindó en el terreno y se dedicó a la fabricación de adobes. Algún tiempo más tarde se le avecindó un velador de las minas de arena, con su familia. En el lapso de diez años se había juntado alrededor de una docena de famlias, todas dependiendo del trabajo de la fábrica de adobes. El dueño decidió fraccionar y vender quince lotes pequeños a los pobladores, quienes construyeron inmediatamente sus viviendas y formaron el núcleo original de Cerrada del Cóndor.

Hacia fines de los años cuarenta se estaba urbanizando toda la zona vecina, ya que el crecimiento de la ciudad de México había comenzado a incorporar las villas de San Ángel y Mixcoac. Como la barriada se encontraba situada en una ladera abrupta no fue codiciada por los fraccionadores y permaneció al margen de este desarrollo urbanó. Durante los años cincuenta llegaron treinta familias, en su mayoría de obreros en las minas de arena, en la fábrica de adobes y en las construcciones vecinas. Además, llegaron numerosos parientes de los pobladores originales, muchos de ellos directamente del campo. Posteriormente a 1960 se produjo un crecimiento acelerado de la Cerrada, ya que se unieron 111 familias, más unas 25 familias que no fueron incluidas en este estu- 
dio por haber abandonado la barriada durante el lapso de la investigación (1969-1971).

Finalmente la fábrica de adobe y las minas de arena cerraron, y sus dueños se convirtieron en rentistas de la barriada, aunque sin dejar de residir en ella. Cada poblador paga arriendo por su casa o por el terreno o por ambos a la vez, con la excepción de una minoría de propietarios. Al concluir la investigación. Cerrada del Cóndor contenía 176 unidades domésticas. Se hizo un muestreo total, es decir, todas las unidades domésticas fueron censadas en el transcurso del estudio.

\section{ORÍGENES DE LOS POBladores}

El $70 \%$ de los jefes de familia y sus esposas (para abreviar, los designaremos en lo sucesivo como "los pobladores") son de origen rural, es decir, migraron a la región metropolitana de la ciudad de México desde pueblos de menos de 5000 habitantes (Unikel, 1968: 1-18). El 30\% restante se compone de hijos de migrantes rurales nacidos en el Distrito Federal, o de habitantes de antiguos pueblos del sur del Distrito Federal, hoy incorporados al área urbana. Estos últimos podrían calificarse de "migrantes pasivos", puesto que migraron del campo a la ciudad sin moverse de su lugar.

El $86 \%$ de los migrantes de origen rural migraron directamente a la ciudad de México, sin detenerse en puntos intermedios de migración. Esta elevada proporción rige para todas las edades. Por lo demás, cerca de un $75 \%$ de los migrantes se trasladaron a la ciudad en grupos familiares y solamente un $25 \%$ eran solteros. Los migrantes rurales procedían del sector más pobre del campesinado. Dieciocho estados se encuentran representados en la barriada, aunque los estados de Guanajuato, México y San Luis Potosí representan el $56.6 \%$ de los migrantes, seguidos por Veracruz, Zacatecas e Hidalgo con 6 a $7 \%$ cada uno. La casi totalidad de los pobladores migrantes declararon que habían sido campesinos sin tierras en sus pueblos de origen, o que sus tierras habían sido insuficientes para su propia subsistencia.

A su llegada al Distrito Federal, los migrantes no poseían ni ahorros ni aptitudes para ganarse la vida. Un $34.5 \%$ de los jefes de familias y sus esposas eran analfabetos, mientras que el $8.7 \%$ conocían los rudimentos de la escritura aunque nunca habían ido a la escuela. Otro $33.4 \%$ poseía de uno a tres años de escolaridad. Por lo tanto, cabe afirmar que más de la mitad de los migrantes de origen rural eran analfabetos funcionales. En cambio, el analfabetismo entre los pobladores nacidos en el Distrito Federal es significativamente menor. Un $16.8 \%$ de estos últimos no habían tenido ninguna escolaridad, y de entre ellos casi la mitad $(7.2 \%)$ lograron aprender solos los rudimentos de la lectura y la escritura. Más adelante veremos que existe una correlación significativa entre la escolaridad y el nivel económico medido en términos de tipo de ocupación, entradas y posesiones materiales.

Cuando los migrantes llegan a la ciudad se hospedan normalmente en casas de parientes. La presencia de un pariente en la ciudad es posiblemente el factor más consistente dentro de todo el proceso de migración. La función de dicho pariente o parientes determina en gran medida la nueva vida de la familia migrante en la ciudad, incluyendo el lugar que 
escojan como residencia dentro del área metropolitana, el nivel económico inicial que ocupen, y el tipo de trabajo que logren obtener. El imperativo económico de "arrimarse" a algún pariente en la ciudad no tiene escapatoria. El período de residencia inicial en casa de un determinado pariente podrá ser variable, pero los cambios de residencia sucesivos también suelen efectuarse en función de otros núcleos de parientes avecindados en el Distrito Federal. En los casos de familias aisladas, casi invariablemente se termina por atraer a una o más familias de parientes que compartirán el mismo domicilio o residirán en la misma vecindad.

\section{Un ejemplo de migración en grupo: Villela}

Entre la treintena de unidades domésticas procedentes del estado de San Luis Potosí hay un total de $\mathbf{2 5}$ originarias de la hacienda-ejido Villela, municipio de Santa María del Río. Todas estas familias están emparentadas por lazos consanguíneos o afines. La historia migratoria del grupo Villela servirá de ejemplo para ilustrar el proceso tal como se le observa en Cerrada del Cóndor.

La migración inicial de Villela se remonta al principio del decenio de 1950, cuando dos jóvenes de dicho ejido decidieron ir a probar suerte en la capital de la República. Al encontrar trabajo en la fábrica de adobes se avecindaron en Cerrada del Cóndor, y un año más tarde uno de ellos trajo de Villela a su hermana y a dos sobrinas con sus respectivos hijos. Posteriormente, estas sobrinas trajeron a su madre y. hermanos, y así sucesivamente. El ejemplo fue seguido por otras dos familias de Villela, que terminaron emparentadas al grupo familiar inicial mediante lazos de matrimonio o compadrazgo. Uno de los migrantes iniciales, después de cambiar de ocupación varias veces, tuvo la fortuna de encontrar trabajo como colocador de alfombras. Como todos los migrantes posteriores se alojaban inicialmente en casa de sus parientes, quienes los alimentaban y aconsejaban durante la etapa inicial de su estadía en la ciudad, el resultado fue que casi todos los hombres del grupo Villela trabajan hoy como colocadores de alfombras. Este proceso puede observarse muy generalmente en otras redes familiares y no solamente en el caso de Villela. Así, por ejemplo, en una red familiar todos los hombres son pulidores de lápidas para sepulcros; en otra red, todos son panaderos; en otra, albañiles, y así sucesivamente.

Los pobladores originarios de Villela siguen formando una comunidad estrechamente unida en la barriada. Ellos fueron quienes fundaron la asociación local más antigua: el Club de Futbol Villela, cuyos tres equipos entrenan constantemente y participan en torneos interurbanos. Existe un contacto social intenso entre las familias de Villela y se practica mucha ayuda mutua. Todos los migrantes expresan satisfacción en cuanto a los resultados positivos de su migración, y no se advierte nostalgia alguna por Villela, ni siquiera por parte de las abuelas, según las cuales "allá nos moríamos de hambre".

\section{Movimientos dentro de la ciudad}

Se ha afirmado en ocasiones que los migrantes a la ciudad de México tienden a gravitar hacia las vecindades densamente pobladas del centro 
de la ciudad (Turner y Mangin, 1968). Esta hipótesis no ha sido confirmada en nuestro estudio de Cerrada del Cóndor. Por el contrario, la residencia inicial del migrante es determinada por el lugar de residencia de los núcleos de parientes quienes lo precedieron. En general, puede afirmarse que los migrantes tienden a cambiar de residencia dentro de un mismo sector de la ciudad; por ejemplo, los actuales pobladores de Cerrada del Cóndor proceden generalmente del área sur de la zona metropolitana, sea que allí nacieron o que migraron inicialmente a dicha área. Son muy pocos los residentes de Cerrada del Cóndor que poseen siquiera un conocimiento superficial de otras zonas de la ciudad, incluyendo el centro de ella./En especial, las mujeres y los niños raramente traspasan los límites de la barriada y su conocimiento de la ciudad es muy limitado./

El mecanismo de los movimientos de residencia dentro del área urbana há sido estudiado en detalle. Se comprobó que una familia típica de la barriada cambiaba de residencia cada cinco años en promedio, durante los diez o quince años que siguieron al matrimonio. Algunas familias seguían cambiando indefínidamente. En gran parte, estos cambios de residencia parecen deberse al desalojo, causado por el crecimiento urbano en dirección al sur de la ciudad; además, existe el impulso de encontrar mejores condiciones económicas o de buscar la cercanía de parientes más a su gusto. La rotación demográfica en Cerrada del Cóndor es apreciable: durante el período del estudio se produjo la migración de 25 a 30 familias y la inmigración de unas 40 familias nuevas. Es preciso recordar que la barriada ha sido desdeñada por los fraccionadores y representa, por decirlo así, un área de refugio para gentes desalojadas por el proceso de crecimiento urbano.

Con todo, la gran mayoría de los nuevos pobladores de Cerrada del Cóndor obedecen meramente a la atracción ejercida por parientes avecindados en la barriada. Estos parientes les han informado acerca de la disponibilidad de alojamiento barato y les han ofrecido ayuda mutua, condición sin la cual la vida en una barríada se hace casi imposible. Vemos entonces que la presencia de parientes sigue siendo un factor determinante para la migración interna dentro del área urbana, como lo ha sido para la migración campo-ciudad. En cuanto a las familias nucleares que migran por su cuenta, atraídas por perspectivas económicas o motivos similares, no tardan en atraer a sus parientes de la ciudad o directamente del campo. Los nuevos migrantes rurales son reclutados normalmente en ocasión de las visitas a sus pueblos nativos, ya que los pobladores suelen mantener un contacto regular con el campo. Estas visitas ocurren generalmente en días de fiesta.

En conclusión, podemos afirmar que cada migrante es un agente que ayuda a otros migrantes a establecerse en la ciudad, o a cambiarse de un punto a otro dentro de la ciudad. Esta ayuda consiste en alojamiento permanente o temporal, alimentos, información, colocación en el trabajo, y apoyo moral, y es la base para un sistema más permanente de intercambio que se describirá más adelante.

\section{ECONOMÍA DE LA VIDA EN LA BARRIADA}

Las características económicas generales de la barriada son de una pobreza extrema. Un cuarto típico mide tres por cuatro metros y contiene 
una o dos camas para el uso de todos los miembros de la familia. Puede existir también una mesa, una silla, una cócinẩ de petróleo o de gas, y a veces un televisor (el 33\% de las unidades residenciales tienen televisión). En la barriada existen tres llaves de agua públicas; además, en contados casos hay agua corriente en una vivienda o vecindad. Prácticamente no hay alcantarillado o drenaje municipal: las cuatro quintas partes de la población de la barriada utilizan la barranca misma como letrina pública. Un gran basurálo público adyacente a la barriada dificulta aún más la situación sanitaria.

No hay instalación eléctrica legal. No hay calles pavimentadas y el tránsito se efectúa por callejones de drenaje entre las unidades habitacionales. Para clasificar estas viviendas se proponen los siguientes cuatro niveles económicos observados en Cerrada del Cóndor:

Nivel $A$ : tres cuartos o más, agua corriente, baño o letrina, construcción de tabique, piso de cemento o baldosas, muebles de comedor y sala, artefactos eléctricos tales como máquina de coser, de lavar o refrigenerador; estufa de gas.

Nivel B: dos cuartos, piso de cemento, no hay agua corriente, letrina o baño común; algunos muebles tales como un armario o baúl, una mesa con varias sillas, algún artefacto eléctrico; estufa de gas.

Nivel $C$ : 10 mismo sin artefactos eléctricos (exceptuando radio o televisor); muebles de baja calidad; estufa de petróleo.

Nivel $D$ : un cuarto con o sin lugar exterior para cocinar; no hay muebles, salvo la cama o camas y ocasionalmente una mesa o silla rústicas; no hay artefactos eléctricos, con excepción de radio o televisor; estufa de petróleo.

Las pruebas estadísticas mediante tablas de contingencia demuestran que los cuatro criterios utilizados en la clasificación anterior (tipo de vivienda, tipo de cocina, muebles y artefactos eléctricos) eran consistentes y estaban muy altamente correlacionados. La distribución de niveles económicos en Cerrada del Cóndor es la siguiente:

$\begin{array}{llr}\text { Nivel A } & 7.8 \% \\ \text { Nivel B } & 8.9 \% \\ \text { Nivel C } & 23.8 \% \\ \text { Nivel D } & 59.5 \%\end{array}$

Además, se comprobó que el nivel económico estaba fuertemente coł relacionado con otros indicadores económicos, tales como el tipo de ocu pación. El total de obreros no especializados, artesanos, sirvientes y co merciantes ambulantes corresponde casi al total de los niveles $\mathrm{C}$ y $\mathrm{D}^{\mathrm{h}}$ (véase el cuadro 1).

Los trabajadores no calificados incluyen albañiles y otros obreros de la construcción (exceptuando a los maestros de obra), pintores, trabajadores en minas de arena, obreros de tabiquerías, ayudantes de panadero, de chofer, de colocadores de alfombras, jardineros, y otros obreros no especializados que trabajan como jornaleros por el salario mínimo diario o cantidades menores. Los artesanos y trabajadores calificados son jornaleros independientes o maestros, tales como los maestros de obra, panaderos, maestros electricistas, choferes, maestros pulidores de lápidas, 


\section{Cuadro 1}

DistribuCIón OCUPACIONAL DE 177 JEFES DE UNIDADES DOMÉSTICAS

\begin{tabular}{|c|c|c|c|c|}
\hline & \multicolumn{2}{|c|}{ Hombres } & \multicolumn{2}{|c|}{ Mujeres } \\
\hline & Núnero & total & Námero & total \\
\hline Trabajadores no calificados y aprendices & 51 & 32.9 & 1 & 4.5 \\
\hline Obreros industriales & 16 & 10.3 & - & - \\
\hline Artesanos y trabajadores califioados & 48 & $\begin{aligned} 31.2 \\
3.2\end{aligned}$ & $\overline{12}$ & 54.6 \\
\hline $\begin{array}{l}\text { Servicios } \\
\text { Comerciantes }\end{array}$ & $\frac{3}{7}$ & 4.5 & 4 & $\begin{array}{l}34.0 \\
18.2\end{array}$ \\
\hline Empleados & 8 & 5.1 & 1 & 4.5 \\
\hline Rentistas & 5 & 3.3 & 1 & 4.5 \\
\hline Cesantes & 15 & 9.7 & 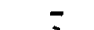 & - \\
\hline Dueñas de casa & $\overline{5}$ & - & 3 & 12.7 \\
\hline
\end{tabular}

carpinteros, zapateros, colocadores de alfombras, herreros, alfareros y similares, quienes ganan salarios más altos pero cuya seguridad de trabajo es generalmente tan baja como la de los anteriores. Algunos de estos maestros han logrado establecerse con una clientela regular y trabajan con sus ayudantes propios, que son generalmente parientes.

Los obreros industriales son trabajadores de baja categoría en diversas industrias, tales como vigilantes, porteros, lavadores de coches y peones; a pesar de sus bajos ingresos, poseen una entrada semanal o mensual segura y alguna seguridad social. En cuanto a las ocupaciones de servicios, ellas incluyen a los meseros, aguadores, vigilantes, repartidores, y sirvientas domésticas. Los comerciantes incluyen a toda clase de vendedores ambulantes, ninguno de los cuales goza de entradas fijas ni de seguro social. Los empleados son generalmente peones de sueldo fijo, por ejemplo, los recolectores de basura, barrenderos y otros empleados municipales, como también algunos con empleos privados. Éstos poseen una seguridad de trabajo relativamente alta y gozan de ciertas prestaciones. Los rentistas están representados por seis unidades domésticas cuya manutención se deriva principalmente de las rentas de propiedades en la barriada.

Casi un $10 \%$ de los jefes de unidades domésticas declararon ser cesantes a la sazón de la encuesta. Por otra parte, más del $60 \%$ de aquellos que declararon estar trabajando también admitieron que la cesantía intermitente por períodos variables de tiempo representaba para ellos una situación normal. Esta mayoría de trabajadores carece de obligaciones formales y puede faltar a labores por uno o más días sin necesidad de rendir cuentas a nadie. En resumen, la mayoría de la población activa de la barriada se compone de trabajadores intermitentes (designados localmente como "eventuales"), que carecen de seguridad de trabajo, de entradas fijas y de seguro social. Viven su existencia de día a día, a semejanza de unos "cazadores y recolectores" en el medio urbano. Económicamente están representados principalmente por el nivel D definido antes.

Las estadísticas muestran que más de la mitad de los pobladores en el nivel $D$ son analfabetos, que ninguno de ellos es propietario de su casa y terreno, y que los dos tercios de ellos pagan arriendo por ambos conceptos. Todas las unidades domésticas en este grupo constan de un solo cuarto; el número promedio de personas por cuarto es de 5.4 con 
cocina interior, y de 6.2 si la cocina se encuentra fuera del cuarto. Más del $75 \%$ de los casos reconocidos de alcoholismo pertenecen al grupo D.

En comparación, prácticamente todos los miembros del grupo A son dueños de sus casas y terrenos. En su gran mayoría, han nacido en el Distrito Federal o han vivido en él muchos años. Casi no existe analfabetismo en este grupo, ya que la mayoría de sus integrantes tienen más de tres años de estudios. Sus ocupaciones son generalmente del tipo más elevado, tales como rentistas, empleados, comerciantes y obreros industriales, con el distintivo común de una mayor seguridad ocupacional. Más de la mitad de las unidades domésticas del grupo A contienen a dos o más personas trabajando. Los hombres eran abstemios o bebedores moderados.

Los niveles $\mathrm{B}$ y $\mathrm{C}$ son intermedios, aunque pueden distinguirse fácilmente entre sí. Por ejemplo, el nivel B es netamente urbano en cuanto al tipo de vivienda, muebles y estilo de vida en general, mientras que el nivel $\mathrm{C}$ es todavía rural en casi todos estos aspectos. La diferencia se reconoce al primer golpe de vista. La transición de nivel $\mathrm{C}$ a nivel $\mathrm{B}$ no depende sólo de los medios económicos sino también de la aculturación al medio urbano; por lo tanto, el tiempo de residencia en la ciudad es un factor muy significativo. Esto resulta comprensible si se considera que las diferencias de ingresos entre los diferentes niveles no alcanzan valores absolutos apreciables, de modo que aun la unidad doméstica más próspera podría quedar arruinada si uno de sus integrantes fuera borracho. Las esposas reciben un dinero semanal para el gasto de la casa y no tienen conocimiento directo de los ingresos del marido. Cuando la esposa trabaja, el total de sus ingresos contribuye a los gastos del hogar; lo mismo sucede cuando trabaja el hijo o la hija. En cambio, la contribución del esposo para incrementar el nivel económico de la familia suele limitarse a la adquisición de ciertos artefactos importantes (televisor, refrigerador) que se paga a plazos. Con todo, si el marido tiene ingresos estables y permite que la esposa trabaje, esta condición puede ser suficiente para impulsar un ascenso económico relativamente rápido de la unidad doméstica. Como esto implica cierta asimilación cultural a la vida urbana, se observa que la transición del nivel $\mathrm{C}$ al nivel $\mathrm{B}$ se produce raramente antes de cumplirse los diez años de residencia en la ciudad.

\section{ORganización SOCIAL}

El patrón de organización social de la barriada será descrito a continuación. En su mayoría, la familia nuclear reside inicialmente con parientes, sea compartiendo una misma unidad doméstica (familias extensas, $46.7 \%$ ), o bien integrando una familia compuesta $(27.4 \%)$. Estas familias compuestas viven en grupos de unidades domésticas contiguas que comparten una zona exterior común para lavado, cocina y juegos de los niños. A diferencia de las familias extensas, cada familia nuclear dentro de un grupo compuesto funciona como una unidad económica separada. Una familia compuesta debe contener por lo menos dos familias nucleares emparentadas por consanguinidad o por afinidad.

Las familias extensas (por ejemplo, dos hermanos con sus respectivas familias) podrán compartir el mismo techo temporalmente o bien en 
forma más permanente, como en el caso de las parejas recién casadas que viven en casa de los padres del novio o de la novia. Para los efectos de esta clasificación, cualquier grupo de cuartos que posee una sola puerta de entrada privada es considerado como una unidad doméstica; en cambio, una vecindad se considera generalmente como un grupo de varias unidades domésticas, porque su portón es de uso público. Cada familia extensa contiene por lo menos a dos familias nucleares, que comparten los gastos de arriendo o son dueños de la propiedad en común, y además suelen compartir ciertos gastos del hogar, como la adquisición de un televisor. En ciertos casos se comparten todos los gastos y los alimentos se preparan en común.

Las familias extensas tienden a ser menos estables que las compuestas. En una unidad doméstica extensa, las familias nucleares suelen desprenderse para mudarse a un cuarto adyacente separado, o para juntarse con otro núcleo de parientes. Eventualmente, sin embargo, los que se mudan por razones de falta de vida privada e independencia suelen regresar a la familia extensa o compuesta por la seguridad y ayuda mutua que ofrece. Las cifras de deserción son mucho menores en el caso de las familias compuestas: de 44 familias nucleares que se habían asociado en grupos compuestos desde la iniciación de su vida familiar, solamente siete se alejaron posteriormente para formar unidades domésticas independientes.

Un total de trece parejas iniciaron su vida marital como unidades domésticas independientes en el Distrito Federal. Estos casos de excepción dentro del patrón de organización familiar propuesto representan a individuos nacidos o criados en el Distrito Federal, que tienden a confirmar la regla, ya que tampoco ellos permanecen independientes a la larga: muy pronto tienden a juntarse con parientes para formar unidades extensas o conjuntas. El cuadro 2 resume nuestros datos sobre tipos de

\section{Cuadro 2}

Tipos de unidades domésticas en Cerrada del Cóndor

\begin{tabular}{|c|c|}
\hline Tipo de unidad & Nümero \\
\hline $\begin{array}{l}\text { Unidades domésticas extansas } \\
\text { Familias nuclearos en unidades domésticas compuestas } \\
\text { Familias nueleares independientes } \\
\text { Sin parientes } \\
\begin{array}{l}\text { Con parientes en la barriada } \\
\text { No se sabe } \\
\text { Total }\end{array}\end{array}$ & $\begin{array}{r}29 \\
68 \\
30 \\
28 \\
7 \\
162\end{array}$ \\
\hline
\end{tabular}

organización familiar. Nótese que el tamaño de la muestra difiere ligeramente de la utilizada en el cuadro 1. Estas fluctuaciones son inevitables debido a que las encuestas se practicaron con una diferencia de tiempo de varios meses; pero ello no afecta la validez de los resultados.

El número de unidades domésticas extensas es al parecer bajo, pero debemos recordar que cada unidad doméstica extensa contiene un mínimo de dos familias nucleares. Esto significa que la familia extensa es la forma dominante en la barriada. Las familias nucleares independientes constituyen la minoria: aquellas que viven a distancia de caminata de sus 
parientes esperan generalmente a que se presente una vivienda disponible para integrarse a un grupo familiar compuesto. En estos casos se observa una intensa interacción social (visitas, ayuda mutua) aun antes de que la familia "independiente" esté integrada en el núcleo compuesto.

En el presente trabajo se usa el término "familia nuclear" en un sentido amplio, incluyendo a allegados; generalmente se trata de ancianos, niños de parientes solteras, o parientes solteros recién llegados del campo. Además, la familia nuclear suele incluir a los hijos de una unión anterior de la madre. En dos casos, todos los hijos en la familia nuclear procedían de un matrimonio anterior. Existen, además; familias nucleares incompletas, es decir, que carecen de uno de los esposos o de hijos. Ocho parejas sin niños vivían independientemente en la barriada; en su mayoría se trataba de parejas mayores cuyos hijos estaban casados. Si se excluye a las familias extensas, donde la situación es demasiado compleja para ser analizada en detalle, el $76.8 \%$ de las familias nucleares restantes eran completas. En el $23.2 \%$ restante, la mayoría eran parejas de recién casados y parejas de ancianos. Concluimos que las formas dominantes de organización familiar en la barriada son la familia extensa y la familia nuclear completa. Todo intento de distinguir las familias nucleares que integran una familia extensa es necesariamente arbitrario; una recopilación tentativa, hecha sin pretensión de rigor, dio un promedio de 2.8 familias nucleares por familia extensa.

Para resumir, podemos describir la organización social de la barriada como un conjunto de redes familiares que se van congregando y disgregando mediante un proceso dinámico. No existe estructura oficial de la comunidad. No hay autoridades locales, ni se observan mecanismos de control interno. El principio rector de la organización social es la cooperación entre las redes de parientes. El proceso dinámico antes aludido comporta un patrón de evolución de la unidad doméstica extensa haciá la compuesta; tal patrón puede cuantificarse mediante encuestas que permiten trazar los cambios estructurales en cada unidad doméstica a través del tiempo. Estas encuestas arrojan los siguientes resultados: si nos referimos al estado inicial de residencia de la pareja recién casada, hay un aumento de $29 \%$ en las unidades domésticas compuestas, contra una disminución de $46.7 \%$ en las extensas. La diferencia en estas cifras parece corresponder a las familias nucleares independientes y a aquellas que ya se han desligado del esquema extenso pero que aún no se han allegado a un grupo compuesto. La observación participante ha confirmado que las familias extensas son más características de la etapa inicial de residencia, mientras que las familias compuestas tipifican una etapa posterior, más madura y más estable.

\section{Localidad}

El cuadro 3 permite describir la distribución de las familias nucleares en la barriada, de acuerdo a los criterios de localidad y tipo de unidad doméstica: a) en el momento del matrimonio o del establecimiento de la familia en el Distrito Federal, y $b$ ) en el momento de la encuesta. Nótense las cifras significativamente elevadas en la diagonal del cuadro: de acuerdo con nuestra interpretación, ello no contradice la elevada movilidad entre los diferentes tipos de localidad y de unidades 
domésticas, sino que revela más bien una alta proporción de matrimonios jóvenes que aún no han tenido oportunidad de mudarse.

En palabras, vemos que el estado inicial es frecuentemente patrilocal $(45.5 \%)$, ya que muchas familias de migrantes y muchas parejas recientemente casadas tienden a vivir en casa de los parientes del esposo, sobre todo con sus padres o su hermano. Las familias que se inician como patrilocales raras veces cambian a matrilocales, y viceversa. La

\section{Cuadro 3}

\begin{tabular}{|c|c|c|c|c|c|c|c|c|}
\hline \multirow[b]{2}{*}{$\begin{array}{l}\text { Estado } \\
\text { actual }\end{array}$} & \multicolumn{6}{|c|}{ Estado iniaial } & \multirow[b]{2}{*}{ Neolocalidad } & \multirow[b]{2}{*}{ Total } \\
\hline & $\frac{\mathrm{Pa}}{\frac{\mathrm{Pa}}{\text { Extensa }}}$ & $\frac{\text { ilocalidad }}{\text { Compuesta }}$ & Total & $\frac{\mathrm{Ma}}{\text { Extensa }}$ & $\frac{\text { rilocalidad }}{\text { Compuesta }}$ & $\overline{\text { Total }}$ & & \\
\hline $\begin{array}{l}\text { Patrilocalidad } \\
\text { Extensa } \\
\text { Compuesta } \\
\text { Total }\end{array}$ & $\begin{array}{r}13.7 \\
5.6 \\
19.3\end{array}$ & $\begin{array}{r}0.0 \\
11.8 \\
11.8\end{array}$ & $\begin{array}{l}13.7 \\
17.4 \\
31.1\end{array}$ & $\begin{array}{l}0.6 \\
0.6 \\
1.2\end{array}$ & $\begin{array}{l}0.0 \\
0.0 \\
0.0\end{array}$ & $\begin{array}{l}0.6 \\
0.6 \\
1.2\end{array}$ & $\begin{array}{l}0.0 \\
3.1 \\
3.1\end{array}$ & $\begin{array}{l}14.3 \\
21.1 \\
35.4\end{array}$ \\
\hline $\begin{array}{l}\text { Matrilocalitad } \\
\text { Extensa } \\
\text { Compuesta } \\
\text { Total }\end{array}$ & $\begin{array}{l}1.9 \\
0.6 \\
2.5\end{array}$ & $\begin{array}{l}0.0 \\
0.0 \\
0.0\end{array}$ & $\begin{array}{l}1.9 \\
0.6 \\
2.5\end{array}$ & $\begin{array}{r}6.9 \\
3.1 \\
10.0\end{array}$ & $\begin{array}{r}1.2 \\
10.6 \\
11.8\end{array}$ & $\begin{array}{r}8.1 \\
13.7 \\
21.8\end{array}$ & $\begin{array}{l}0.6 \\
0.0 \\
0.6\end{array}$ & $\begin{array}{l}10.6 \\
14.3 \\
24.9\end{array}$ \\
\hline $\begin{array}{l}\text { Neolocalidad } \\
\text { Total en columna }\end{array}$ & $\begin{array}{r}10.0 \\
31.8\end{array}$ & $\begin{array}{r}1.9 \\
13.7\end{array}$ & $\begin{array}{l}11.9 \\
45.5\end{array}$ & $\begin{array}{r}3.7 \\
14.9\end{array}$ & $\begin{array}{r}1.9 \\
13.7\end{array}$ & $\begin{array}{r}5.6 \\
28.6\end{array}$ & $\begin{array}{l}20.0 \\
23.7\end{array}$ & $\begin{array}{l}37.5 \\
97.8\end{array}$ \\
\hline
\end{tabular}

tendencia estadística más fuerte es la de patrilocal a neolocal, lo que se interpreta simplemente como reflejo del hecho que la residencia inicial es generalmente patrilocal y que el primer movimiento es generalmente neolocal dentro de la misma barriada. Sin embargo, después de varios cambios la mayoría de las familias nucleares gravita hacia la situación de familia compuesta. Estos cambios pueden ser activos (mudanza de unidad doméstica) o pasivos (recibiendo a una familia emparentada en su casa o en unidades domésticas adyacentes). La relación final de patrilocalidad o matrilocalidad es aproximadamente de tres a dos.

Es esencial visualizar el problema de localidad y residencia como proceso dinámico, que depende de las circunstancias económicas, de la etapa en el ciclo vital, de la disponibilidad de viviendas, del las relaciones personales entre parientes, y de otros factores. En general, la elección inicial de parientes para un esquema de convivencia se rige por consideraciones económicas. Posteriormente la pareja tiende a independizarse, sea por problemas con la suegra o la nuera, o simplemente por la falta de vida privada en las condiciones de hacinamiento extremo de la barriada. Pero luego las circunstancias de la vida (nacimiento de hijos, deserción del esposo, pérdida del empleo, etc.) suelen obligar a la familia independiente a regresar a la protección de los parientes. Una solución preferencial es la familia compuesta, ya que combina la cercanía y cooperación de los parientes con una relativa independencia de la familia nuclear. 
regulares entre parientes más allá de los límites físicos de la barriada, contactos que la observación personal confirmó inicialmente y que han sido cuantificados después mediante encuestas en todas las unidades domésticas de la barriada.

El contacto entre parientes dentro del Distrito Federal depende de la distancia física y de la distancia social. Los informantes mencionan prioritariamente a los miembros de su familia nuclear de orientación, y en seguida a sus demás parientes por orden de cercanía física: aquellos que viven en la barriada, luego los que viven en barriadas cercanas, etc. El contacto con un pariente que viva a dos horas en autobús y no sea particularmente íntimo, resultará tal vez insignificante, y puede llegar a perderse del todo al cabo de una generación. La madre es con frecuencia el factor de unión entre tales parientes, y se pierde el contacto después de su fallecimiento. En cambio, cuando existe una relación afectiva fuerte los parientes ejercerán una atracción mutua constante, hasta lograr que uno de ellos cambie su residencia en la cercanía del otro.

Otro factor que influye en la intensidad del contacto entre parientes es el desnivel socioeconómico. Podemos citar el comentario de una informante que decía tener escaso contacto social con sus hermanas, casadas con obreros industriales especializados: "le voy a decir la verdad: a mí no me gusta ir a verlas porque ellas se visten muy'bien y yo no puedo y pues, me da pena". La informante es hija de un obrero especializado y se casó con un hombre que "no terminó primaria y está peor" que los cuñados. Sus propios padres se habían opuesto al matrimonio porque "no tenía oficio, aunque fuera de chofer, peluquero o carpintero". Pero ella "lo queria, y nos fuimos a vivir con mis suegros", es decir, en la misma barriada de Cerrada del Cóndor. La informante ingresó en la red de parentesco de sus suegros y se lleva bien con ellos. Al principio compartían la misma casa pero hoy viven cerca, porque "siempre es mejor que cada cual tenga su casa".

El contacto entre parientes de la ciudad y del campo ya ha sido mencionado en una sección anterior, y ha sido descrito en otras investigaciones (Simic, 1970; Buechler, 1970; Lomnitz, 1969; Van Kamper, 1971; Butterworth, 1962; Mangin, 1959). Las visitas al pueblo natal se hacen en días de fiesta, tales como el Día de la Madre, el Día de Muertos, o la fiesta del santo del pueblo. Los migrantes solteros suelen regresar luego a la ciudad en compañía de algún hermano menor, hermana o primo a quienes mantienen hasta conseguirles una colocación. Los migrantes casados suelen mantener una pequeña propiedad agrícola en común con algún hermano, y hacen que sus visitas coincidan con la época de la cosecha o de otros trabajos importantes. Una mayoría de migrantes envía dinero a sus padres o parientes cercanos en el campo, y se mantienen enterados de los chismes locales. Eventualmente se las arreglan para promover la migración de sus familiares a la ciudad, de manera que se produce una corriente migratoria durante varios años. Los parientes se alojan con el poblador de barriada hasta que pueden defenderse por su cuenta.

I Con el fiempo el contacto con el campo se va desvaneciendo. Alrededor de la cuarta parte de los informantes declararon que tenían aún parientes en el campo pero que habían perdido todo contacto: "no veo a mis parientes desde hace 18 años que me casé y me vine a México con mi marido"... "Desde que murió mi mamá no he regresado; mi padre se volvió a casar y no me llevo con la madrastra"... "Todos los her- 
manos se vinieron; antes iba y les llevaba dinero; ahora ya no voy"... "Desde que murieron mis padres y abuelos ya no voy." Otros migrantes siguen manteniendo un contacto significativo con el campo por razones sentimentales (peregrinaciones a la tumba de la madre en el Día de los Muertos), además de las razones ya mencionadas.

\section{Agrupaciones locales}

A falta de instituciones centralizadas, la organización de la barriada comporta ciertos tipos diferentes de agrupaciones, a saber: a) redes familiares; b) equipos de futbol; c) el centro médico, y d) asociaciones temporales. Las redes familiares se describirán más adelante en forma detallada, en apoyo de nuestra tesis de que constituyen la comunidad efectiva para el individuo en la barriada. Las redes incluyen a los miembros de una familia extensa o compuesta, pero pueden asimilar además a vecinos mediante una relación de compadrazgo. Según veremos, estas redes han desarrollado un sistema de reciprocidad, que proporciona una explicación consistente del hecho de la supervivencia de grandes masas de población en las condiciones adversas de la vida en la barriada.

Las formas restantes de organización en la barriada son rudimentarias. Existen cuatro equipos de futbol en Cerrada del Cóndor; tres de ellos pertenecen a la macro-red familiar de Villela descrita antes. El cuarto equipo es más reciente y sus miembros provienen de la juventud de la barriada sin distinción de orígenes familiares. Parece significativo que este equipo hubiera adoptado el nombre de "México". Los equipos de futbol representan uno de los escasos vehículos de contacto entre los hombres de Cerrada del Cóndor y los habitantes de otras zonas de la ciudad. Después de cada competencia se producen sesiones de camaradería en las que se bebe juntos y se fortifica el espíritu de amistad y la solidaridad del equipo.

El Centro Médico de Cerrada del Cóndor merece mención aparte. Este Centro fue organizado y financiado por un grupo de damas de clase media residentes de una colonia vecina, con ayuda de la Parroquia. Con posterioridad, el Hospital Infantil de México decidió proporcionar personal médico y otras ayudas, que fueron retiradas últimamente. Pese a sus modestos medios el Centro se había convertido en una parte importante de la vida de la barriada, donde los niños eran acogidos a todas horas del día y en donde muchas mujeres y muchachas pudieron recibir el consejo de una trabajadora social comprensiva y atenta. No existen otras organizaciones comunitarias en Cerrada del Cóndor, con la posible excepción del peregrinaje al Santuario de Atotonilco, organizado cuatro veces al año por un antiguo residente de la barriada. No se trata de una organización permanente, y aunque todos los peregrinos son residentes de Cerrada del Cóndor, no van cada vez los mismos individuos. Esta peregrinación es de índole religiosa y su duración es de una semana.

No existen recursos establecidos para solucionar los problemas comunes que suscita la vida de la barriada. Sucede a veces que un grupo de vecinos se reúne para solucionar asuntos específicos: esto ha ocurrido en unas tres o cuatro oportunidades desde que existe la barriada. La primera vez se trataba de obtener la instalación de una llave pública de agua, ya que los residentes de la Cerrada tenían que caminar casi dos 
kilómetros hasta el agua más cercana. En otra oportunidad, se reunió un grupo de señoras para solicitar una audiencia con la Primera Dama, con el objeto de presentar una queja por unos derrames de petróleo de una refinería, que estaban causando incendios en la barranca. Estos casos excepcionales de cooperación ponen de relieve el hecho de la falta de todo esfuerzo cooperativo organizado para enfrentar los problemas de la comunidad.

Esta sección no ha de concluir sin mencionar brevemente la membresía de los pobladores en organismos urbanos o nacionales. Los contactos con tales organismos son insignificantes. La principal articulación de la barriada con la cultura urbana mexicana se produce a través del trabajo, y a través de los medios de comunicación masiva tales como el radio y la televisión. Desde luego que la escuela es de importancia destacada para la población infantil y juvenil. Las lecturas de la gente adulta están casi enteramente limitadas a la prensa deportiva, las historietas cómicas y las fotonovelas.

Cerca de una décima parte de la población adulta masculina pertenece al sistema de seguro social. Alrededor de un 5\% son miembros de algún sindicato. En general, puede afirmarse que un número muy pequeño de pobladores pertenece a cualquier grupo organizado a escala nacional, sea de tipo político, religioso o social.

\section{REDES DE INTERCAMBIO}

Ya se ha mencionado que son muy escasos los pobladores de la barriada que se aventuran a adentrarse en la ciudad más allá de lo indispensable para su trabajo. Pocos son los que conocen el centro de la ciudad y sus monumentos. En cuanto a las mujeres y los niños, su conocimiento de la ciudad suele limitarse al mercado, la iglesia más cercana y el domicilio de alguno que otro pariente. Los compañeros de parranda de los hombres son también parientes y vecinos; muy excepcionalmente incluirán a algún compañero de trabajo de fuera de la barriada. De hecho, la comunidad del individuo está determinada por el parentesco y la residencia.

Según Barnes (1954: 39-58), una red se define como un campo social constituido por relaciones entre personas. Estas relaciones se encuentran determinadas mediante criterios subyacentes al campo. Barnes consideraba la extensión de una red como esencialmente ilimitada, pero Mayer (1962: 576-592) demostró que ciertos tipos de migrantes se encierran en una red limitada de relaciones personales. En el caso de Cerrada del Cóndor tenemos redes definidas por criterios de proximidad, distancia social e intercambio de bienes y servicios. Desde luego, el criterio básico desde nuestro punto de vista será la existencia de una corriente permanente de intercambio recíproco de bienes y servicios; el criterio de proximidad física debe interpretarse principalmente como un requisito previo para que pueda producirse este modo de intercambio, puesto que la distancia lo impediría hasta entre parientes cercanos.

Cada red se compone de familias nucleares, no de individuos. Como una definición operacional inicial, señalaremos una red como un grupo de familias nucleares vecinas entre sí, que practican el intercambio recíproco sistemáticamente entre ellas. Se identificaron en total 47 redes de 
este tipo en Cerrada del Cóndor. Desde el punto de vista de su estructura de relaciones sociales, hay 30 redes basadas en consanguinidad y afinidad, 9 redes mixtas (de parientes y no parientes), y 8 redes de familias no emparentadas. En el cuadro 4 damos la distribución del número de familias nucleares por cada red; el promedio es cercano a cuatro. Por supuesto que este número no es fijo en una red determinada, sino que fluctúa con el tiempo. Una red podrá constituirse inicialmente con dos o tres familias nucleares, y con posterioridad podrá crecer hasta llegar a un tamaño excesivo; en tal caso, una parte de la red podrá separarse y formar una metástasis en otro lugar de la barriada o fuera de ella, iniciando así un proceso similar. La pertenencia a una red es tan general en la barriada que hubo menos de diez familias nucleares no adheridas a ninguna red. La mayoría de las familias señaladas como "independientes" o "neolocales" en los cuadros 2 y 3 están también asociadas en redes, aunque no con parientes. Debido al proceso de crecimiento y metástasis de redes, sucede que algunas redes poseen relaciones mutuas de parentesco. Por ejemplo, la macro-red de Villela se compone de cinco redes, con un total de 25 familias nucleares.

Cuadro 4

NÚMERO DE FAMILIAS NUCLEARES POR RED

\begin{tabular}{cc}
$\begin{array}{c}\text { Número de familias } \\
\text { nucieares }\end{array}$ & Frecuencia \\
\hline 2 & 9 \\
3 & 15 \\
4 & 9 \\
5 & 7 \\
6 & 2 \\
7 & 0 \\
N.S.S. (families extensas no contabilizables) & 5 \\
Total & 47 \\
\hline
\end{tabular}

Al interior de cada red se produce una alta intensidad de intercambio recíproco de bienes y servicios sobre una base diaria; en cambio, los recursos de la macro-red se utilizan más bien en ocasiones rituales, para casos especiales tales como la colocación en el trabajo, y para las expresiones de solidaridad familiar o en los círculos de bebedores. El intercambio recíproco que se produce entre familias pertenecientes a diferentes redes es menos frecuente, debido a que no existen suficientes recursos en la barriada para mantener un intercambio diario generalizado con un grupo tan numeroso de familias.

El intercambio recíproco dentro de una red se practica sobre un pie de igualdad entre todas las familias participantes. Además, cualquiera de estas familias podrá mantener relaciones diádicas de intercambio con familias fuera de su red, que pertenezcan o no a otras redes. Estas relaciones diádicas tienen importancia porque a través de ellas se genera el mecanismo para atraer a otras familias a la red, o para dividir la red en caso de que ésta hubiera rebasado su tamaño óptimo.

En todos los casos el tipo de intercambio en una red es uno de reciprocidad. La reciprocidad varía desde una comunidad de recursos (en el caso de las familias extensas) hasta una reciprocidad diádica en el caso 
de redes de vecinos no emparentados entre sí. Hay también una forma intermedia, común en las redes de tipo compuesto, que combina la comunidad de ciertos recursos con el intercambio diádico entre todos o algunos de sus miembros. Por lo tanto, el tipo de reciprocidad depende de la distancia social. Se identificaron ocho redes compuestas únicamente por vecinos no emparentados entre sí: en estas redes el tipo de intercambio era diádico. Además, cualquiera de las familias miembros podía mantener una relación de reciprocidad diádica con una familia de otra red, pero tal relación era diferente en que no implicaba a los demás miembros de su red. En algunas redes compuestas, que contenían familias emparentadas y no emparentadas, se observó reciprocidad diádica (uno a uno) y poliádica (uno con todos); en estos casos, la reciprocidad diádica era más frecuente que en las redes compuestas únicamente por parientes (familias compuestas), en las que dominaba el intercambio poliádico y la mancomunión de bienes.

La red constituida como familia extensa suele practicar un intercantbio generalizado de bienes y servicios, en el que se comparten informalmente los recursos necesarios para arriendo, diversiones, uso común de la cocina, cuidado común de niños y muchos otros. Cada familia nuclear contribuye a la red según sus posibilidades y recibe según los recursos disponibles; no se llevan cuentas de ninguna especie entre los miembros de la red. En cambio, en la familia compuesta cada familia nuclear tiene su propio techo y su economía separada; hay un intercambio diario e intenso de comida, útiles y herramientas, y dinero. La reciprocidad en ambos casos responde a un acuerdo tácito: cada familia participante debe contribuir en la medida de sus posibilidades, aunque la devolución de lo recibido no esté explícitamente sancionada. Sucede, por ejemplo, que una familia nuclear participante en una red compuesta logre prosperar por sobre el nivel de las demás; en tal caso, es posible que su contribución esperada supere la posible utilidad recíproca que le ofrece su membresía en la red, y la familia próspera podrá dejar de solicitar y de ofrecer ayuda, como se verá en el siguiente caso.

Historia de un caso: una red de tipo compuesto incluye a dos hermanas A y B, casadas con dos hermanos. Un vecino no emparentado es también miembro de la red. Una tercera hermana (C) fue traída del campo y vivió en casa de A hasta encontrar empleo como sirviente doméstica. En sus días de salida $C$ continuaba visitando a $A$. Luego una sobrina casada vino del campo y se integró a la red. Inicialmente vivieron en casa de $\mathrm{A}$ hasta que obtuvieron un cuarto adyacente y trabajo para el marido, todo gracias a la ayuda de A. Todos los hombres en esta red trabajan de pulidores de lápidas. Cuando $\mathrm{C}$ quedó encinta dejó su empleo y volvió a casa de $\mathrm{A}$; tuvo su bebé y regresó a trabajar, dejando su infante al cuidado de su hermana durante el día.

Mientras sucedía todo esto, el nivel económico de la hermana $\mathrm{B}$ había ido ascendiendo continuamente. Su esposo no bebía y en cambio hacía inversiones en el mejoramiento del hogar. Además, fue progresando en el trabajo y ascendió a trabajador especializado (colocador de lápidas). Por último, B dejó de pedir favores dentro de su red, y se negó a prestar dinero pretextando que no tenía. Sus hermanas, su sobrina y su vecina gradualmente dejaron de pedirle favores, y sus esposos tomaron la misma actitud. Al cabo de un tiempo B encontró un cuarto con servi- 
cios de tipo urbano, a pocas cuadras de la barriada, y se mudó. Su actual nivel económico se estima de tipo " $B$ " dentro de nuestra clasificación.

En cuanto a la hermana $\mathrm{C}$, encontró marido en la barriada y se fue a vivir con él. Con todo, C seguía frecuentando diariamente a su hermana durante las horas en que su marido trabajaba; cuando ella estaba trabajando la hermana le cuidaba el niño. Esta situación seguía vigente al concluir la investigación. El intercambio de favores era especialmente intenso con la hermana y la sobrina, y en menor escala con los vecinos, a pesar de que esta familia había hecho compadrazgo por partida doble y mantenía un intercambio muy activo dentro de la red. A1 desocuparse un cuarto adyacente $\mathrm{C}$ empezó la labor de convencer a su marido para que se unieran a la red. En caso de tener éxito se anticiparía un intercambio más activo entre $\mathrm{C}$ y la vecina.

\section{Objetos de intercambio}

De acuerdo a mi observación, el intercambio en las redes concierne principalmente lo siguiente:

a) Información, íncluyendo datos e instrucciones para asuntos de migración, trabajo y alojamiento; chismes, y orientación para la vida urbana.

b) Entrenamiento y ayuda para empleo, incluyendo el proporcionar instrucción laboral para establecer a un pariente como competidor. Por ejemplo, un colocador de alfombras o albañil introducirá a su cuñado recientemente llegado del campo como su ayudante, le enseñará su oficio, compartirá con él su salario y eventualmente le cederá parte de su clientela en caso de tenerla.

c) Préstamos de dinero, alimentos, ropa, herramientas y cualquier otro tipo de artículos.

d) Bienes compartidos en común, tales como un televisor o una letrina, que los hombres hubieran construido en colaboración.

e) Servicios, tales como el hospedaje de parientes del campo y de viudas, huérfanos y ancianos; el cuidado de enfermos y de niños de madres que trabajan, etc. La ayuda mutua entre los hombres incluye la colaboración en la construcción de viviendas y el acarreo de materiales; entre los niños, el acarrear agua y hacer toda clase de mandados.

f) Apoyo emocional y moral, tanto en las situaciones rituales (casamientos, bautizos, funerales) como en situaciones diarias (chismes entre las mujeres, grupos de "cuates" bebedores entre los hombres). Es indispensable hacer ver que gran parte de la vida social en la barriada se basa en la afiliación a una determinada red. Esta interacción constante entre los miembros de la red produce una preocupación constante por los asuntos del prójimo, y una vigilancia sobre cada uno de sus actos. Queda poco lugar para la vida privada.

\section{Intercambio asimétrico}

Todas las relaciones entre miembros de una red son esencialmente relaciones de igualdad social. Generalmente las familias que componen una red tienen y carecen de los mismos tipos de recursos. Por ello, el intercambio adquiere la forma de reciprocidad, siempre sobre una base 
estrictamente igualitaria. Por otra parte, cuando una familia dentro de una red dispone de más recursos económicos que las demás, esta base igualitaria se altera o se destruye. Tal situación provoca tres tipos de patrones diferentes, según el grado de urbanización.

a) El patrón rural tradicional consiste en la redistribución bajo forma de alcohol. Este patrón, que puede observarse por ejemplo en las redes de Villela, aparece como estrechamente asociado a la ideología del "cuatismo", y resulta efectivo en prevenir toda preeminencia económica por parte de cualquier miembro de la red, ya que ninguno puede llegar a acumular ahorros.

b) Un patrón intermedio, representado por dos casos aislados en Cerrada del Cóndor, es la emergencia de la figura del "cacique", si bien en forma rudimentaria. El poder del "cacique" se basa principalmente en su influencia para colocar a los migrantes en distintos trabajos, más que en su posición económica. Estos "jefes" de barriada podrían considerarse más bien como mediadores entre el campo y la ciudad; pero su función en Cerrada del Cóndor aparece como relativamente secundaria.

c) Por último, tenemos el patrón descrito en la historia del caso precedente, el caso de una familia nuclear en proceso de urbanización. Esta urbanización se traduce en un cambio en el nivel de vida (del nivel C al B), junto con un cambio significativo en la ocupación del esposo en dirección hacia un empleo más especializado y más estable. Entonces la red deja de desempeñar una función útil para la familia nuclear, y se convierte más bien en un estorbo. Las múltiples obligaciones de la vida en la red ya no son percibidas como pertinentes al progreso económico. En todos los casos observados, los lazos con la red se cortaron después de un período señalado por una fuerte reducción en la intensidad de intercambio; la familia urbanizada acabó por mudarse fuera de la barriada.

Tomados en su conjunto, estos tres patrones representan evidencia de las más fuertes en apoyo de nuestra interpretación de las redes en la barriada, como estructuras económicas que representan una respuesta específica de las poblaciones marginales a la inseguridad económica dentro del ambiente urbano.

\section{Mecanismos de refuerzo}

Estas estructuras económicas forman la base de un sistema social, el de la organización en redes. Tal organización social viene a ser reforzada a su vez por una ideología y por ciertas instituciones, tales como el compadrazgo y el cuatismo. La base económica de las redes es el intercambio de bienes y servicios entre sus miembros: cuando cesa este intercambio la red se desintegra. La estructura social erigida sobre esta base depende de la proximidad física y social de sus miembros. Desde un punto de vista ideal las redes se compondrían de vecinos emparentados entre sí.

De hecho, muchas redes contienen miembros no emparentados cuya lealtad necesita ser reforzada mediante el parentesco ficticio (compadrazgo) u otros mecanismos que se analizarán a continuación. Incluso entre parientes las relaciones no siempre son seguras: con frecuencia surgen diferendos económicos y personales en las condiciones de extrema pobreza y hacinamiento. Por lo tanto, los mecanismos de refuerzo se encuentran presentes en todas las redes analizadas. 
El uso del compadrazgo para reforzar relaciones de redes existentes o en perspectiva es universal. En Cerrada del Cóndor los compadres mantienen pocas obligaciones formales como tales. Dice un informante: "Para elegir padrino para el hijo de uno se le pide a una persona que sea decente y buen amigo; si es a una pareja, que estén bien casados. Que sean pobres para que no se diga que uno los eligió por interés." Entre 579 compadres de bautismo (el tipo más frecuente de compadrazgo en la barriada), 150 eran parientes que vivían en cercana vecindad, y 200 eran vecinos no emparentados. Otros 92 eran parientes que vivían fuera de la barriada, sea en el Distrito Federal o en el campo: en otras palabras, posibles miembros futuros de las redes. En todos los casos de compadrazgo los factores dominantes fueron el parentesco y la vecindad. Este patrón igualitario difiere llamativamente de ciertos patrones rurales que han sido descritos, y en los que se tiende a elegir como compadres a personas más altamente colocadas que uno (Foster, 1969; Forbes, 1971).

La importancia del compadrazgo como mecanismo de refuerzo se refleja además en la variedad de tipos de compadrazgo que se observa en la barriada. En orden de mayor a menor importancia se han detectado, con el correspondiente número de casos: bautismo (579), confirmación (291), comunión (79), boda (31), corona o entierro (16), santo (13), quince años (10), Niño Dios (8), evangelios (8), graduación de primaria (4), hábito (3), sacramento (2), escapulario (1), cruz (1) y de San Martín (1). Todos estos tipos de compadrazgo sirven para señalar ocasiones rituales o del ciclo de la vida, incluyendo enfermedades, mandas, etc. Las obligaciones entre compadres se describen de la siguiente manera: "Deben tratarse siempre con respeto y deben saludarse siempre que se encuentren." Idealmente, algunos tipos de compadrazgo comportarían obligaciones económicas considerables, tales como hacerse cargo de un ahijado si el padre llegara a morir; pero este tipo de obligaciones ya no se toman muy en serio en la barriada.

Las razones para escoger a un compadre determinado pueden ser de tipo positivo o también negativo. Entre las razones positivas se halla el propósito de extender la red; por ejemplo, hay muchos casos de compadrazgo entre los miembros de una macro-red, es decir, entre miembros de diferentes redes que están emparentados entre sí. Otras razones son: "Son conocidos y los queremos... Nuestros maridos son muy buenos amigos... Somos concuños y nos llevamos bien... Somos vecinos... Los hemos escogido porque queremos ser más amigos... Ellos nos ayudaron... Nos ayudamos." Algunos ejemplos de razones negativas son las siguientes: "Les pedimos para vivir en paz con ellos... Fue la manera de reconciliarnos con mi cuñada... Les pedimos para poder mantenerlos a distancia." En un caso que se analizó a fondo, la informante había sido novia de juventud de un cuñado de su hermana, quien vive en otra red de la misma barriada. La relación entre ambas redes era tensa debido a los celos de la esposa de su ex novio. Para cimentar las buenas relaciones entre los concuños la informante invitó a su ex novio y esposa a que fueran padrinos de su hijo. Esto puso su relación por sobre toda sospecha, en vista de que los compadres deben usar de formalidad y tratarse de "usted" en toda ocasión.

El cuatismo es la forma mexicana de amistad masculina. Nuestra información sobre cuatismo fue obtenida principalmente por intermedio 
de las esposas, en vista del carácter exclusivo y celoso que tradicionalmente reviste la relación. Los cuates (del término nahua para "gemelos") son amigos que pasan el tiempo juntos, conversan, beben, juegan naipes o futbol, miran televisión juntos, se invitan mutuamente en los restaurantes y se entretienen juntos: ante todo, son compañeros de parranda. Las mujeres se encuentran totalmente excluidas de la relación. Una esposa "no se atrevería" a pedirle un favor directamente al cuate de su marido.

La ayuda entre cuates se encuentra regulada por la distancia social. Entre parientes la ayuda es más incondicional que entre vecinos. En general, los cuates tienden a prestarse mutuamente dinero, a ayudarse en obtener empleo, a colaborar en los trabajos de sus viviendas, y a apoyarse mutuamente en las peleas. Al igual que el compadrazgo, el cuatismo es prácticamente universal, y el hombre que no tiene ni compadres ni cuates está perdido. En un total de 106 unidades habitacionales enca-J bèzađàs pör hombres los cuates del jefe de la unidad se distribuían de la siguiente manera: 86 eran grupos de vecinos inmediatos, 9 eran grupos mixtos (en que algunos cuates eran vecinos y otros vivían más lejos), y 11 eran grupos que no vivían en inmediata vecindad de la unidad habitacional. Dos jefes de unidades habitacionales no habían tenido tiempo aún de tener cuates en la ciudad.

Además, 21 de los grupos de cuates se componían exclusivamente de parientes; otros 20 grupos se componían de parientes y de vecinos, y 45 grupos contenían solamente a no-parientes. Está claro que los grupos de cuates se basan esencialmente en el sector masculino de las redes ya descritas; pero además pueden incluir a otros vecinos, a amigos y a compañeros de trabajo. La existencia del cuatismo como mecanismo de refuerzo en las redes constituye una prueba de que las tales redes no están basadas simplemente en la afiliación femenina como podría suponerse a primera vista. Por el contrario, muchas redes aparecen dominadas por los maridos, según lo refleja además el predominio de la patrilocalidad (véase antes el cuadro 2 ). Si las redes estuvieran basadas exclusivamente en las formas más diarias y visibles del intercambio de bienes y servicios practicadas por las mujeres, sería sorprendente encontrar una correlación tan elevada entre las redes y los grupos de cuates, como es la que se comprueba en la realidad. Insistimos en que las unidades básicas de las redes son las familias nucleares y no los individuos: todos los miembros de cada una de las familias nucleares integrantes participan activamente en la relación.

El compañerismo en la bebida es muy importante y suele tener precedencia ante las relaciones amorosas. El hecho mismo de emborracharse juntos comporta un lazo fuerte dentro de un grupo. Esta relación se extiende en todas las direcciones sociales; por ejemplo, las propuestas de compadrazgo suelen originarse en el curso de una sesión de bebida. Desde el punto de vista psicológico el hecho de beber juntos es un testimonio de confianza mutua absoluta, ya que implica potencialmente una confesión de todas las debilidades (véase Lomnitz, 1969; Butterworth, 1972). Desde un punto de vista económico el cuatismo encierra un mecanismo de redistribución en forma de bebida, que mantiene la igualdad económica de todos los cuates. Finalmente, desde el punto de vista social el cuatismo refuerza las redes existentes y extiende la influencia de las redes 
en todas direcciones, puesto que puede haber miembros de diferentes redes en un mismo círculo de bebedores.

Ejemplo: En su entrevista inicial, M. S. estaba literalmente echando las pertenencias de su marido fuera de su cuarto, declarando que era un borracho sin remedio y que ya no lo "aguantaba". La segunda entrevista se produjo una semana más tarde. En esta oportunidad M. S. confesó apenada que su marido seguía viviendo con ella "porque es cuate de mis dos hermanos y siempre salen a tomar juntos". La implicación era que sus hermanos tomarían partido por su cuate y no por ella, especialmente tratándose de un problema de bebida, y que el problema amenazaba con desbaratar la red.

En tercer lugar, la ideología de ayuda mutua constituye otro importante factor de refuerzo de las redes. En respuesta a preguntas directas, pocos informantes están dispuestos a describir su propia utilización de las redes de ayuda mutua, y en cambio todos manifiestan estar siempre listos para ayudar a sus parientes y vecinos. El deber de otorgar este tipo de ayuda se encuentra revestido con todas las cualidades morales positivas, y constituye la justificación ética que cimenta las relaciones personales en las redes.

Cualquier individuo que se negara abierta o indirectamente a proporcionar ayuda dentro de una red es enjuiciado en los términos más severos, y se convierte en blanco de todos los chismes. La gente se encuentra siempre al acecho de cualquier cambio en la situación económica de sus vecinos, que pudiera indicar o prefigurar alguna alteración en las relaciones internas de la red. El chisme y la envidia representan los dos mecanismos utilizados para mantener las relaciones de igualdad. Cualquier signo de egoísmo o exclusivismo basta para echar a rodar los comentarios y las habladurías, y nunca falta quien haga entrar la oveja negra al redil.

Ejemplo: Al iniciar una amistad personal con la señora V. me fue posible colocarla como sirvienta en casa de un profesor visitante, y también le regalé algo de ropa usada. Un día las vecinas observaron que yo le entregaba un paquete con ropa. En la ocasión de mi próxima visita se puso a llorar, y me contó que las vecinas la habían ido a ver para acusarla de egoísta y exigirle su parte de la ropa, diciendo que yo les había asegurado que la ropa era para todo el grupo. Indudablemente, los demás miembros de la red habían visto con envidia y preocupación cómo el buen trabajo y los presentes de ropa estaban colocando a V. por encima del nivel económico normal de la red.

\section{Macro-redes}

Si pudiéramos comparar a la familia nuclear con el átomo de la sociedad, la red de parentesco sería la molécula de la estructura social en la barriada. Existen fuertes afinidades entre los átomos al interior de una molécula, pero ello no excluye que se produzcan ligas y afinidades entre moléculas diferentes. Desde luego, es posible que se unan varias moléculas de idéntica composición para formar un polímero, o sea, lo que hemos llamado una "macro-red" en la barriada. Ya se mencionó un ejemplo de macro-red: el conjunto de cinco redes de pobladores originarios de Villela, con un total de 25 familias nucleares. Como todos los 
miembros de esta macro-red son parientes, las afinidades mutuas entre las redes son especialmente fuertes, aun cuando la intensidad del intercambio de red a red pueda ser menor de lo que es dentro de cada red individual. Como evidencia de intercambio dentro de la macro-red podemos citar la alta incidencia de las relaciones de compadrazgo, y la existencia del club de futbol basado en afiliación con la macro-red.

Estructuralmente hablando, las relaciones entre miembros de una macro-red son diádicas. Si partimos de la existencia de dos pobladores emparentados, sus relaciones de intercambio siempre serán importantes debido a la escasa distancia social que los separa. Al fijar su residencia en distintos puntos de la barriada, cada uno de ellos podrá llegar a agrupar sendos núcleos de parientes, y se formará una macro-red compuesta por dos redes. Por otra parte, si uno o ambos parientes se integran por afinidad a redes no emparentadas, no se producirá una macro-red a pesar de que los dos parientes podrán continuar manteniendo las mismas relaciones diádicas entre sí. En otras palabras, la macro-red se caracteriza por la existencia de relaciones diádicas de reciprocidad de todos los componentes de una red con todos los de la otra.

\section{Reciprocidad y confianza}

Los tipos de reciprocidad entre miembros de una barriada se encuentran determinados por el factor que hemos llamado "confianza" (Lomnitz, 1971). La confianza depende de factores tanto culturales (distancia social) como físicos (cercanía de residencia) y económicos (intensidad del intercambio). Hay casos en que la cercanía física y la intensidad del intercambio prevalecen por sobre la distancia social; por ejemplo, un "cuate" podrá ser de mayor confianza que un pariente que vive muy lejos y sólo aparece muy de vez en cuando.

Las categorías formales de la distancia social se encuentran culturalmente definidas, ya que implican "una serie de categorías y planes de acción" (Bock, 1969:24), que determinan el comportamiento esperado en un individuo. Estas categorías y planes de acción sólo pueden describirse etnográficamente, porque representan una parte esencial de la cultura o subcultura de un grupo o subgrupo. Dos individuos están cerca en la escala de confianza al grado de que comparten el mismo conjunto de expectativas de comportamiento, o sea que su cercanía concuerda con sus propias categorías formales de distancia social.

Estas expectativas incluyen, entre otras cosas, un tipo específico de reciprocidad, que varía desde la comunidad incondicional de bienes hasta la falta total de cooperación. La escala de confianza nos da, en cierto modo, una medida del grado de cumplimiento o realización de dichas expectativas. Por lo tanto, el grado de confianza no está determinado de una vez por todas, sino que puede variar en el curso de una relación. En el caso de la reciprocidad tribal, descrito por Sahlins (1965), el esquema de intercambio es relativamente rígido. En cambio, en la clase media chilena (Lomnitz, 1971), los límites entre las categorías eran bastante fluidos y cada individuo tendía a cambiar sus niveles de confianza según las fluctuaciones de la amistad personal. La situación en la barriada de Cerrada del Cóndor debe calificarse de intermedia entre 
la relativa fluidez de la clase media chilena y la relativa rigidez de la situación tribal.

Cuando dos individuos pretenden establecer una relación social prescrita culturalmente a través de la categorías formales de distancia social, deben vencer alguna resistencia. En el caso de la barriada esta resistencia es 1a distancia física, obstáculo principal al contacto social. Por esta razón, el factor cercanía se vuelve una componente esencial de la confianza; la cercanía estimula y el alejamiento inhibe la confianza. Por supuesto que la cercanía física por sí misma no puede nunca reemplazar la cercanía social. Se observa, por ejemplo, que dos vecinos originarios de diferentes regiones o capas socioculturales difícilmente establecerán una relación de confianza íntima. Por otra parte, dos parientes o paisanos incrementarán considerablemente su nivel de confianza por el hecho de hacerse vecinos.

En conclusión, la confianza es variable y flexible mientras que la distancia social es formal e invariable. La confianza resulta del juego de factores físicos, económicos y personales, incluyendo el hecho de llevarse o no llevarse bien con algunas personas; estos factores actúan sobre el modelo ideal de comportamiento. Podríamos decir que mide la diferencia entre la distancia social ideal y la real. Cuando esta diferencia se vuelve bastante grande puede llegar a sancionarse formalmente, por ejemplo, confiriendo el compadrazgo a un vecino de mucha confianza. El lenguaje común reconoce también las diferencias en la escala de confianza, tal como en el térmíno "cuate" que transforma a un amigo íntimo en un hermano gemelo ficticio.

\section{Discusión TEÓRICA: El PAPEL DE LAS REDES DE INTERCAMBIO EN EL CONTEXTO DE LA MARGINALIDAD}

La marginalidad urbana no es propia solamente de las sociedades subdesarrolladas, como ya lo señalara Quijano (1970). Así, en las sociedades industriales existe marginalidad debido al desplazamiento de ciertas capas sociales por la mecanización y automatización de los medios de producción. Estas poblaciones numéricamente crecientes pierden toda esperanza de ser absorbidas por el mercado de trabajo, y se vuelven cargas permanentes de los servicios de previsión social. De hecho no representan un proletariado de reserva, sino más bien una población sobrante que es un subproducto indeseable del sistema.

Según Quijano, esta situación se agrava considerablemente en los países subdesarrollados, en que el ritmo y el patrón del desarrollo industrial son dictados desde el extranjero. La dependencia económica de estos países introduce un factor de inestabilidad, que causa una hipertrofia de las grandes ciudades a expensas del campo. La disponibilidad de materia prima y de fuentes de trabajo barato atrae un rebalse de capital hegemónico a las antiguas sociedades preindustriales. Así se produce 1) un desnivel cada vez mayor entre las ciudades "modernas" rodeadas de inmensos cinturones de miseria, y las áreas rurales "tradicionales" sumidas en la mayor pobreza; 2) el monopolio de las nuevas técnicas industriales por una élite laboral relativamente reducida, mientras que la gran masa de campesinos y pequeños artesanos es desplazada de sus ocupaciones tradicionales; 3) la modernización superficial, que estimula la 
explosión de población y anula todos los esfuerzos por absorber gradualmente a los marginados en la fuerza de trabajo regular. Por otra parte, la competencia de la mano de obra barata de estos países contribuye a agravar el problema del desempleo en los países desarrollados. Podemos concluir, por lo tanto, que el proceso de marginalización no es transitorio f sino que es intrínseco al sistema.

Hasta aquí la interpretación de Quijano, quien identifica al sistema capitalista en general ( $y$ al desarrollo industrial dependiente de la América Latina posterior a 1945 en particular) como causante del fenómeno de la marginalidad. En cambio, Adams (1970: 89-94; 1972) señala que dicho fenómeno no es exclusivo del capitalismo, sino que ocurre en toda sociedad de masas que se encuentra en el proceso de desarrollo económico y de cambio tecnológico. Según este autor, todo incremento de organización social se logra a costa de una mayor desorganización en algún sector o sectores de la misma sociedad o de sociedades dependientes de ella. Dialécticamente hablando, el orden crea el desorden, según el mismo principio por el cual el trabajo crea entropía. Si suponemos una fuerza laboral no diferenciada, podemos utilizarla para organizar un proletariado industrial con niveles de especialización altamente diferenciados y con formas centralizadas de organización; pero al efectuar este cambio estaremos generando una población marginada compuesta por aquellos elementos que no han sido asimilados y que ya no tienen utilidad dentro del nuevo sistema más avanzado, Adams compara este proceso a la producción de desechos y contaminantes por un sistema industrial.

Las siguientes características de las capas urbanas marginadas de América Latina son comunes también entre los residentes de Cerrada del Cóndor: a) desempleo o subempleo; b) falta de ingresos estables; c) nivel económico bajo, generalmente el más bajo entre la población urbana. Los pobladores de Cerrada del Cóndor son, en su gran mayoría, migrantes de origen rural, migrantes "pasivos" o hijos de migrantes. Generalmente, son jornaleros no especializados —albañiles, por ejemplopagados por día de trabajo, o artesanos o maestros que trabajan a trato y carecen de entradas fijas. Hay también comerciantes ambulantes y sirvientes. Este grupo ocupacional podría describirse como "cazadores y recolectores de la ciudad", ya que viven en los intersticios de la economía urbana, la cual les ha asignado, sin embargo, un lugar y una función específica.

Si este numerosísimo grupo carece de seguridad económica y prácticamente tampoco recibe apoyo de los organismos de previsión social, podemos preguntarnos cómo se las arregla para sobrevivir. Quijano (1970: 87-96), quien se plantea esta misma pregunta, supone la existencia de algún mecanismo de reciprocidad aún no descrito, y que funcionaría entre los grupos marginados. En la próxima sección intentaremos definir y analizar este mecanismo en función de la estructura socioeconómica de la barriada.

\section{La red de intercambio como mecanismo de supervivencia}

Según Polanyi (1968: 127-132) y Dalton (1968: 153) existen tres formas de intercambio de bienes y servicios: 1) el intercambio de mercado, que representa una circulación de bienes y servicios con base en 
la oferta y la demanda, sin implicaciones sociales a largo plazo; 2) la redistribución, en que los bienes y servicios se concentran primero en un individuo o institución, para en seguida distribuirse en la comunidad o la sociedad; 3) la reciprocidad, un intercambio paritario de bienes y servicios como parte integral de una relación social duradera.

E1 análisis de Polanyi destaca la naturaleza reciente de la dominación del mercado sobre otras formas de intercambio (1968: 43-68). Entre los pueblos primitivos y las sociedades tribales, la economía se basa principalmente en la reciprocidad y la redistribución, mientras que el intercambio de mercado se usa sobre todo en el comercio entre tribus o grupos sociales diferentes. Hacia fines de la Edad Media se generalizó en Europa la economía monetaria característica del intercambio de mercado; su apogeo coincide con la revolución industrial capitalista del siglo XIX. Sin embargo, ningún sistema económico opera exclusivamente con uno de los tres tipos de intercambio: uno de ellos, digamos el intercambio de mercado, podrá ser dominante en una época determinada, pero los otros coexisten con él y se encuentran muchas veces representados por instituciones sociales específicas. En las sociedades modernas conocemos ejemplos de instituciones basadas en el mercado (el sistema monetario y de mercadeo), en la redistribución (el sistema de impuestos y de previsión social), y en la reciprocidad (los grupos paritarios).

¿Por qué motivo subsisten estas formas aparentemente arcaicas en una economía moderna de mercado? Según Polanyi, todo sistema basado exclusivamente en el interés individual terminaría por destruirse a sí mismo, ya que la base de la vida social es la cooperación. La crisis del sistema de intercambio de mercado se produce precisamente cuando las expectativas sociales rebasan el nivel en que pueden ser satisfechas para todos los miembros de la sociedad. En la tesis de Polanyi esta crisis se produce a escala mundial a partir de la guerra de 1914, la revolución rusa, el fascismo y la depresión. La consecuencia ha sido una mayor implantación de los mecanismos sociales de redistribución, hasta el punto de tornarse dominantes para el intercambio de bienes y servicios en los países socialistas.

Por otra parte, el papel de la reciprocidad en las sociedades industriales modernas es más difícil de definir. Malinowski (1961: 334-350) y Sahlins (1968: 130-177) lo han hecho para el caso de ciertas tribus primitivas. Otros autores (Gouldner, 1960; Lévy-Strauss, 1967, 289; Mauss, 1954; Homans, 1968) han hecho mención del principio de reciprocidad como base de la vida social, pero este principio no debe confundirse con el modo específico de intercambio de bienes y servicios que Polanyi y Dalton han designado bajo el nombre de "reciprocidad". Ejemplos de reciprocidad institucionalizada se han dado y se siguen dando en sociedades complejas: un ejemplo es la minga, una institución de intercambio recíproco de trabajo en la sociedad incaica. Los antropólogos económicos de la escuela formalista, como Firth (1970), Burling (1962: 804; 813820) y Cook (1968: 188-208) tienden a negarles importancia a la reciprocidad y a la redistribución en las sociedades modernas, ya que según ellos el principio de la maximización de recursos debe servir de guía a todo análisis antropológico moderno de las relaciones económicas. No obstante, en un reciente estudio de la clase media chilena hemos podido demostrar que la reciprocidad continúa practicándose como modo espe- 
cífico de intercambio en sociedades urbanas en vías de industrialización (Lomnitz, 1971). En este caso, la reciprocidad llega a determinar tipos e intensidades de relaciones sociales al punto de que la historia económica de la clase media chilena se vuelve ininteligible si no se toma en cuenta la existencia del "compadrazgo".

Se estima que la población urbana marginal en México puede llegar a cerca de cuatro millones, es decir, una parte muy considerable de la población urbana total del país. Si bien el intercambio de mercado constituye el modo dominante de intercambio en las ciudades, con todas sus contradicciones internas, no existen suficientes mecanismos de redistribución pública o privada para satisfacer las necesidades mínimas de la población marginal.

El individuo marginalizado nada tiene que ofrecer al sistema de intercambio de mercado: ni propiedades, ni habilidades especiales salvo su fuerza de trabajo desvalorizada. Sus posibilidades de integración al proletariado urbano son escasas, puesto que la marginalidad aumenta más rápidamente que el mercado de trabajo industrial. No puede depender del sistema de mercado para sus necesidades más elementales. Su supervivencia depende de su capacidad para crear un sistema de intercambio completamente diferente de las reglas del mercado: un sistema basado en sus recursos de parentesco y de amistad, Este sistema seguirá las reglas de la reciprocidad, una modalidad de intercambio entre iguales, incrustada en una urdimbre de relaciones sociales que persiste en el tiempo y no es pasajera y casual como en el intercambio de mercado.

Los elementos básicos que constituyen los requisitos para la reciprocidad en la barriada son: a) la confianza, o sea una medida de distancia social definida etnográficamente; $b$ ) igualdad de carencias, o falta de recursos; c) cercanía de residencia (Adams y Lomnitz, en preparación). Una consecuencia característica de la relación de reciprocidad es la elaboración de un código moral diferente (y a veces opuesto) al código moral del intercambio de mercado. En una relación de reciprocidad existe un énfasis moral explícito en el acto de dar, o de devolver el favor recibido, antes que de extraer el máximo beneficio inmediato de una transacción. Sabemos que ambos sistemas pueden utilizarse paralelamente en diferentes contextos, puesto que un miembro de una red de intercambio recíproco puede simultáneamente vènder sus servicios o su fuerza de trabajo en el mercado laboral. Pero en último término es la reciprocidad con sus parientes y amigos la que asegura su supervivencia entre los largos y frecuentes intervalos de cesantía, a pesar de que el mercado proporcione todos los recursos económicos. Cuando estos recursos no van acompañados de un mínimo de seguridad, no logran garantizar el sustento. En cambio, si estos recursos intermitentes se comparten entre seis, ocho o diez personas, el grupo sobrevivirá allí donde sucumbiría el individuo.

Las redes que hemos logrado identificar en Cerrada del Cóndor representan relaciones económicas funcionales que maximizan la seguridad y cuyo éxito garantiza la supervivencia para amplios e importantes sectores de la población urbana. Podemos afirmar que la contienda entre los substantivistas y los formalistas es más aparente que real: si bien los sistemas de intercambio de mercado maximizan recursos tangibles, la red de reciprocidad maximiza seguridad. Ambos son indispensables para la supervivencia individual. De paso, esta conclusión pudo haber sido pa- 
sada por alto si la barriada se hubiera estudiado solamente con los métodos de la teoría económica. El enfoque antropológico sostiene que las relaciones económicas son una parte inseparable de la organización social y no pueden analizarse sin un estudio detallado de la organización social.

Tomemos, por ejemplo, el problema de la ingestión de alcohol en Cerrada del Cóndor. No basta, para los efectos de nuestro estudio, demostrar la correlación negativa del exceso en la bebida con el nivel económico y dictaminar que el alcohol impide el progreso económico. Desde el punto de vista sociocultural el acto de beber es básico para la institución del "cuatismo", que a su vez refuerza la cohesión social. Pero el cuatismo es parte de la economía de las redes de la barriada, y su importancia se manifiesta a través de su papel como mecanismo nivelador de diferencias de ingreso. La desigualdad destruiría las relaciones de reciprocidad que se encuentran en la base de las redes; por lo tanto, resulta plausible argumentar que el alcohol cumple una función positiva desde el punto de vista de la maximización de seguridad en las comunidades marginales. El problema no reside en hacer que el individuo beba menos, sino en que pueda darse el lujo de dejar de beber.

Este pequeño ejemplo no pretende agotar el tema del consumo de alcohol en Cerrada del Cóndor. El papel de la ingestión de alcohol en una comunidad de migrantes ha sido tema de una discusión más exhaustiva en otro trabajo (Lomnitz, 1969; 1973). Éste es solamente un ejemplo que demuestra la posibilidad de interpretar erróneamente ciertos indicadores económicos en poblaciones marginales, si estos indicadores se estudian aparte de su propio contexto sociocultural.

\section{BIBLIOGRAFIA}

Adams, N. Richard. 1970. Crucifixion by Power. Austin: University of Texas Press. 1972. Harnessing Tecnology. Mimeografiado.

Barnes, J. A. 1954. "Class Committees in a Norwegian Island Parish", Human Relations, 7, 39-58.

Bock, Philip. 1969. Modern Cultural Anthropology. Nueva York: Alfred A. Knopf Bonilla, F. 1961. "Rio's Favelas: The Rural Slum within the City", Field Staff Reports (East Coast, South American Series): 8 (3).

Burling, R. 1962. "Maximization Theories and the Study of Economic Anthoropology", American Anthropologist, Vol. 64.

Butterworth, D. 1972. "Two Small Groups: a Comparison of Migrants and NonMigrants in Mexico City", Urban Anthropology, Vol. 1, 1.

1962. "A Study of the Urbanization Process among Mixtec Migrants from Tilaltongo in Mexico City", América Indigena, 22:257-74.

Cook, Scott. 1968. "The Obsolete 'Anti-Market' Mentality: A Critique of the Substantive Approach to Economic Anthropology", en Economic Anthropology, compilado por E. E. LeClair, Jr. y L. Schneider, pp. 188-208. Nueva York: Holt, Rinehart and Winston, Inc.

Dalton, G. 1968. "The Economy as Instituted Process", en Economic Anthropology, op. cit., pp. 143-187.

Firth, R. 1970. "Themes in Economic Anthropology", ASA Monographs, Núm. 6, pp. 1-29, $2^{a}$ edición. Edimburgo: T. A. Constable Limited.

Forbes, Jean. 1971. El sistema de compadrazgo en Santa María Belén Atzitzinititán. Tlaxcala. Tesis de maestría. México: Universidad Iberoamericana.

Foster, George. 1969. "Godparents and Social Networks in Tzintzuntzan", Southern Journal of Anthropology, 25:3. 
Gouldner, Alvin. 1960. "The Norm of Reciprocity: a preliminary Statement". American Sociological Review, Vol. 25, 2.

Leeds, A. 1969. "The Significant Variables Determining the Character of Squatter Settlements", América Latina, 12 (3). 1969 a. "Brazil and the Myth of Urban Rurality", en City and Country of the Third World. Comp. por A. J. Field, Cambridge: Schenkman.

Lévi-Strauss, C. 1967. Structural Anthropology. Garden City, N. Y.: Anchor Books, Doubleday and Co. $2^{*}$ edición.

Lomnitz, Larissa. 1969. "Patrones de ingestión de alcohol entre migrantes mapuches en Santiago", América Indigena, 29 (1):43-71.

- 1971. "Reciprocity of Favors among the Urban Middle Class of Chile". en Studies in Economic Anthropology, compilado por George Dalton, Washington: AAA.

Malinowski, B. 1961. Argonauts of the Western Pacific. E. P. Dutton and Co., Inc.

Mangin, W. 1967. "Latin American Squatter Settlements: A Problem and a Solution", Latin America Research Review, 2 (3).

Matos Mar, J. 1968. Urbanización y barriadas en América del Sur. Lima: Instituto de Estudios Peruanos.

Mauss, M. 1954. The Gift. London: Cohen and West, Ltd.

Meyer, P. 1962. "Migrancy and the Study of Africans in Town", American Anthropologist, 64:576-592.

Nichamin, Julies. 1968. "Shantytowns in Latinoamerica: Prospects for Political Change", Papers of the Michigan Academy of Science, Arts and Letters, 53 (2).

Peatti, Lisa R. 1968. The View from the Barrio. Ann Arbor: University of Michigan Press.

Polanyi, K. 1968. "The Economy as Instituted Process", en Economic Anthropology, op. cit., pp. 122-142.

1968a. The Great Transformation. Boston: Beacon Press.

Portes, A. 1972. Rationality in the Slum: An Essay on Interpretative Sociology.

Quijano, A. 1970. Redefinición de la dependencia y proceso de marginalización en América Latina. CEPAL, mimeografiado.

Roberts, B. 1968. "Protestant Groups and Coping with Urban Life in Guatemala City", American Journal of Sociology, 73 (6) : 735-767.

Safa, H. 1964. "From Shantytown to Public Housing: A Comparison of Family Structure in Two Urban Neighborhoods in Puerto Rico", Caribbean Studies. $4(1)$.

Sahlins, M. D. 1968. "On the Sociology of Primitive Exchange", en ASA Monographs, Núm. 1, Comp. por M. Banton, pp. 13-177. Tavistock Publications.

Simic, A. 1970. The Peasant Urbanities: A Study of Rural-Urban Mobility in Serbia. Berkeley: Tesis doctoral.

Turner J. y W. Mangin. 1968. “The Barriada Movement”, Progressive Architecture, mayo.

Unikel, Luis. 1968. "Ensayo sobre una nueva clasificación de población rural y urbana en México", Demografía Y EConomía, Vol. II, 1, pp. 1-18.

Valentine, Charles A. 1972. Culture and Poverty. The University of Chicago Press, Chicago.

Van Kamper, R. 1971. Tzintzuntzan migrants to Mexico City. Tesis doctoral. Berkeley. 